\title{
MARGINAL COST OF PUBLIC FUNDS AND REGULATORY REGIMES: COMPUTABLE GENERAL EQUILIBRIUM EVALUATION FOR ARGENTINA
}

\section{EL COSTO MARGINAL DE LOS FONDOS PUBLICOS Y LOS REGIMENES REGULATORIOS: EVALUACION DE EQUILIBRIO GENERAL COMPUTABLE PARA LA ARGENTINA*}

\section{OMAR O. CHISARI**}

Universidad Argentina de la Empresa and CONICET

\section{MARTIN CICOWIEZ***}

Universidad Nacional de La Plata

\begin{abstract}
We estimate the Marginal Cost of Public Funds for Argentina using a Computable General Equilibrium (CGE) model, assessing the sensitivity of the results to the existence of alternative regulatory regimes (price-cap and cost-plus) for public utilities subject to regulation. The estimates are in the range of international studies, and we confirm that the results are sensitive to the regulatory regime, to the presence of exempted goods, the existence of unemployment, the elasticity of labor supply, as well as to the degree of capital mobility, between sectors and internationally. In addition, our results highlight the existence of differential propensity to finance public projects under price-cap regimes vis-à-vis cost-plus regimes.
\end{abstract}

Keywords: Marginal cost public funds, regulation, general equilibrium, Argentina.

JEL Classification: H22, D58, L5.

\footnotetext{
* We are grateful to Andrés Blanco for his assistance in initial versions of this paper and to Antonio Estache, Gustavo Ferro and to an anonymous referee for their comments.

**ochisari@uade.edu.ar

***martin@depeco.econo.unlp.edu.ar
} 


\section{Resumen}

En este trabajo se estima el Costo Marginal de los Fondos Públicos para Argentina empleando un Modelo de Equilibrio General Computado. Se evalúa la sensibilidad de los resultados respecto de la existencia de regímenes regulatorios alternativos ("price-cap" y "cost-plus") para los servicios públicos regulados. Las estimaciones obtenidas están en línea con la evidencia empírica internacional, y confirman que los resultados son sensibles al régimen regulatorio, la presencia de bienes exentos, la existencia de desempleo, la elasticidad de la oferta de trabajo, como así también al grado de movilidad del capital, entre sectores e internacional. Adicionalmente, los resultados señalan la existencia de diferentes propensiones a financiar proyectos públicos bajo régimen de "price-cap" vis-à-vis regímenes de "cost-plus".

Palabras Clave: Costo marginal fondos públicos, regulación, equilibrio general, Argentina.

Clasificación JEL: H22, D58, L5.

\section{INTRODUCTION}

The Marginal Cost of Public Funds (MCPF) measures the change in social welfare that is generated by a marginal increase in tax revenue. Consequently, a public project must produce marginal benefits higher than the MCPF to be welfare improving. Holding public revenue constant, welfare can be increased by reducing taxes with the highest MCPF and increasing those with the lowest MCPF. Therefore, estimates of the MCPF provide guidelines for reform of tax structures and help to choose how to finance public projects.

An exploration of the most important literature on the MCPF shows that it is usually computed assuming that there are no regulated sectors in the economy. On the other hand, the literature on regulation assumes that the MCPF is independent of the regulatory regime (for example, see Laffont and Tirole's 1993 classical text). Here we analyze the interaction between the tax system and the regulatory regime.

Is the MCPF lower/higher under no regulation, price-cap, or cost-plus? Is there a different propensity in the granting of subsidies and in the financing of public projects under any of the alternative regimes? In this paper, to explore these issues we compute the MCPF for Argentina by implementing a Computable General Equilibrium (CGE) model calibrated to the year 2004. This is relevant because regulated sectors represent a significant share of total GDP in Argentina, as well as in many other countries. Moreover, competition policy and public intervention even in competitive markets often determine implicit caps on prices via threat of regulation. Actual regulatory regimes are not pure, and seem to respond to a combination of short term price-cap 
and long run cost-plus regime. Even the pass-through of taxes to regulated prices is imperfect or delayed. Therefore, our work tries to highlight how the choice of the actual regulatory regime impacts on the marginal cost of public funds itself.

We compare the effects of a change in the tax system under different regulatory regimes and test the sensitivity of our results to different specifications for the labor market (i.e., full employment and unemployment), as well as to alternative assumptions on factor mobility between sectors, and -in order to take into account the results when dividends are paid to foreign residents- between the domestic economy and the rest of the world.

The paper is organized as follows. The next Section is devoted to a brief discussion of the literature on the calculation of the MCPF in developing and developed countries. Section 3 explains how a CGE model can be adapted to consider two alternative regulatory regimes: price-cap and cost-plus. Section 4 presents a description of our CGE model. In Section 5 we report our main results and present estimates of the MCPF under different assumptions. Finally, Section 6 concludes. In the Appendix we present the analytical version of the CGE model.

\section{LITERATURE ON THE MCPF}

The formal analysis of the MCPF started with the work of Pigou (1928). ${ }^{1} \mathrm{He}$ argued that, in order to determine the optimal level of public spending, the government must take into account the distortionary effect of raising taxes. In turn, the distortionary effect of raising taxes creates a deadweight loss or welfare cost that depends on the elasticities of the labor and capital supply (hours worked, job type, human capital accumulation, and so on), the composition of the consumption basket, and the propensity to save. ${ }^{2}$ As we show below, all these elements have an important role in CGE calculations, and of course in our own estimates.

Browning (1976) explains that "the marginal cost of public funds is the social opportunity cost of government spending". He shows that the MCPF includes any expenditure that arises from the tax system. Following this, it can be said that there is a more comprehensive definition of MCPF, one that includes the administrative costs of collecting government revenue and other "hidden costs", like tax evasion and corruption (Usher, 1991). However, the lack of data, especially in developing countries, constitutes an important barrier in conducting estimations that include all these effects.

Atkinson and Stern (1974) point out that the MCPF can be decomposed into the substitution and income effects, which they call the "distortionary effect" and the "revenue effect", respectively. The "distortionary effect" is the deadweight loss

\footnotetext{
1 "Expenditure should be pushed in all directions up to the point at which the satisfaction obtained from the last shilling expended is equal to the satisfaction lost in respect to the last shilling called up on government service" (Pigou, 1928).

2 See Feldstein (1997).
} 
mentioned above. The "revenue effect" depends on the outcome of the "income effect" on tax revenue. ${ }^{3}$

Ballard and Fullerton (1992) distinguish two methods to calculate the MCPF. According to the first one, known as the Pigou-Harberger-Browning approach, one has to compare distortions in the tax system with an equal-revenue lump-sum tax. ${ }^{4}$ This approach is more concerned with the structure of the tax system than with the overall level of taxation. The second method, the Stiglitz-Dasgupta-Atkinson-Stern approach (Stiglitz and Dasgupta, 1971), states that the MCPF not only depends on the substitution effect but also on the income effect. It assumes that the increase in revenue is used to finance public projects, which are independent of the supply of labor. 5

Our paper relies on the Pigou-Harberger-Browning approach to calculate the MCPF. In particular, we use Browning's (1976) approach by assuming that increases in public spending are considered as lump-sum transfers to the households. 6

Since the publication of Harberger's seminal work (Harberger, 1962), the number of studies that calculate the distortions induced by the tax system has grown considerably. The development of computational economics made it possible to use general equilibrium models to calculate the MCPF. For example, Warlters and Auriol (2005) have recently estimated the MCPF for several African countries using a small CGE model. In Table 1 we show literature estimates of the MCPF for various countries. The estimations are in a range that goes from 0.48 (when there is a marginal benefit of public funds) up to 2.65 , although they are not strictly comparable as their methodologies differ. We will see that our results for Argentina are in that range.

As mentioned above, we investigate whether the calculation of the MCPF should consider the existence of alternative regulatory regimes. The literature on the economics of regulation assumes that the MCPF is independent of the regulatory regime (Laffont

3 Ballard and Fullerton (1992) claim that "Since the income effect of wage taxation increases work effort and therefore increases government revenue, it works toward a lower marginal cost of public funds".

4 Musgrave takes a "differential analysis" view to calculate the MCPF. Depending on the assumptions, this approach can also be included in the "Balanced-Budget Analysis" if we assume that the government provides private goods publicly -see Stiglitz (2000). As Browning (1987) poses it, "if the marginal government spending provides benefits that are a perfect substitute for the disposable income of taxpayers, then the spending is only an income effect that is equivalent to a lump sum transfer... This may be largely correct in cases involving government provision of schooling, medical care, pensions, and other things taxpayers would purchase with their disposable income if the government did not provide them". However, as Atkinson and Stern (1974) note, the level of complementarity of public spending and private spending will be determined by the type of goods that the public sector provides. If the government provides public goods, public spending will complement private goods and Browning's argument does not hold.

5 With this method the "balanced-budget analysis" approach (Musgrave, 1959) prevails, which incorporates the increase in government spending in calculating the MCPF.

6 However, it will be observed that the MCPF can be less than one in our calculations, as it happens in the Stiglitz-Dasgupta-Atkinson-Stern version. As explained below, the reason can be found in the distributive story in an economy open to foreign capital, when tax rebates are restricted to reach only domestic agents. 


\section{TABLE 1}

\section{ESTIMATIONS OF THE MARGINAL COST OF PUBLIC FUNDS}

\begin{tabular}{|c|c|c|c|}
\hline Country & Tax Instrument & Estimate & Source \\
\hline Australia & Labor & $1.19-1.24$ & Campbell and Bond (1997) \\
\hline Australia & Labor & $1.28-1.55$ & Findlay and Jones (1982) \\
\hline Australia & Capital & $1.21-1.48$ & Diewert and Lawrence (1998) \\
\hline Australia & Capital & $1.15-1.51$ & Benge (1999) \\
\hline Bangladesh & Sales & $0.95-1.07$ & Devarajan et al. (2001) \\
\hline Bangladesh & Imports & $1.17-2.18$ & Devarajan et al. (2001) \\
\hline Cameroon & Sales & $0.48-0.96$ & Devarajan et al. (2001) \\
\hline Cameroon & Imports & $1.05-1.37$ & Devarajan et al. (2001) \\
\hline Canada & Commodities & 1.25 & Campbell (1975) \\
\hline Canada & Labor & 1.38 & Dahlby (1994) \\
\hline Canada & Labor & $1.39-1.53$ & Fortin and Lacroix (1994) \\
\hline China & Sales & 2.31 & Laffont and Senik-Leygonie (1997) \\
\hline India & Excise & $1.66-2.15$ & Ahmad and Stern (1987) \\
\hline India & Sales & $1.59-2.12$ & Ahmad and Stern (1987) \\
\hline India & Imports & $1.54-2.17$ & Ahmad and Stern (1987) \\
\hline Indonesia & Sales & $0.97-1.11$ & Devarajan et al. (2001) \\
\hline Indonesia & Imports & $0.99-1.18$ & Devarajan et al. (2001) \\
\hline New Zealand & Labor & 1.18 & Diewert and Lawrence (1994) \\
\hline Switzerland & All taxes & $1.69-2.29$ & Hansson and Stuart (1985) \\
\hline United States & All taxes & $1.17-1.56$ & Ballard et al. (1985) \\
\hline United States & Labor & $1.21-1.24$ & Stuart (1984) \\
\hline United States & Labor & $1.32-1.47$ & Browning (1987) \\
\hline United States & All taxes & 1.47 & Jorgenson and Yun (1990) \\
\hline United States & Labor & $1.08-1.14$ & Ahmed and Croushore (1994) \\
\hline United States & All taxes & 2.65 & Feldstein (1997) \\
\hline United States & All taxes & 1.23 & Diewert et al. (1998) \\
\hline United States & All taxes & 1.07 & Browning (1976) \\
\hline United States & All taxes & 1.18 & Browning (1976) \\
\hline
\end{tabular}

Source: Author's elaboration and Warlters and Auriol (2005).

and Tirole, 1993). However, the MCPF is very important in choosing the power of incentives in the regulatory regime; if the MCPF is low, then the cost of transfers to an inefficient service provider is also relatively small. We will see that the hypothesis of independence of the MCPF as regards the regulatory regime can be challenged, particularly when dealing with economies where high distortionary levels of taxation are already present and when these economies are open to the rest of the world. This is also interesting because it can be read in the opposite direction: if the MCPF varies according to the regulatory regime, the design of the optimal regulatory framework will have to take that information into account. 


\section{COMPUTATIONAL REPRESENTATION OF PRICE-CAP AND COST-PLUS UNDER SERVICE OBLIGATION}

The literature on regulatory regimes under asymmetric information assumes that the MCPF is independent of the regulatory regime ${ }^{7}$, and proceeds to select the optimal power of incentives under that assumption. We use our model to evaluate if that assumption is reasonable for a real economy in which regulated sectors represent a significant share of GDP.

Advances in the economics of regulation over the last 30 years are overwhelming. ${ }^{8}$ In the new regulatory economics, information has the role of a scarce factor and the presence of asymmetric information generates rents and distortions that have private and social costs. Thus, the contractual link between the regulator and the regulated firm can be interpreted as a particular case of the broader relationship between the Principal and the Agent within a context of risk under asymmetric information.

Both under "moral hazard" or "adverse selection", it is necessary to design a contract that balances risk sharing and information disclosure. In most models, it is the Principal who designs the contract, and the Agent who accepts or rejects it. The optimal contract is therefore obtained by maximizing the welfare of the Principal (almost always a risk neutral economic agent) subject to constraints that take into account the problem of utility maximization of the Agent. Firstly, the Agent (risk averse) must not obtain a reward (in terms of utility) lower than what he/she could obtain elsewhere in the economy (the Participation Constraint). Secondly, the Agent must not benefit from cheating about his characteristics or actions (the Incentive Compatibility Constraint).

In this context, two "pure" methods are usually proposed to regulate the prices of licensed or privatized activities which are natural monopolies, price-cap and costplus regulation. Under the first one, the price of the product or service is fixed and the regulated firm faces all the risk. If costs rise, the regulator will not rescue the firm in any way (e.g., by raising the price or giving a direct subsidy to the firm). On the other hand, if costs fall, the firm will obtain profits to be distributed as dividends to shareholders. The price-cap regime reduces the monitoring cost by granting the firm a market incentive to maximize efficiency in its internal processes. However, although it reduces the rents from asymmetric information, the price-cap regime increases the risk premium necessary to induce the firm's participation. In contrast, under the cost-plus regime, the firm is assured a certain rate of return as the regulator rescues

7 See for example Laffont and Tirole's classical text (Laffont and Tirole, 1993). The reciprocal effect has been considered for example by Desai and Dharmapala (2004); they look at how the power of incentives to managers depends on the tax system.

8 For example, the introduction of the revelation principle made an extraordinary simplification possible by showing that there is no loss of generality if the number of contracts is reduced as much as possible to the number of types of agents. A more general theory for natural monopolies (based on the subadditivity of costs to justify its existence) was developed, and Ramsey pricing was extended to take into account "revenue cap" and access fees. Additionally, the relationship between efficient regulation and income distribution was more firmly established (based on the concepts of service obligation and of universal service). 
the firm in the case of a negative shock; but the ever-present risk makes it difficult to discriminate between increases in genuine and speculative costs. Therefore, the firm has no incentive to reduce costs and increase efficiency. This results in potential efficiency losses and the need to collect revenue through distortionary taxes to cover the firm's deficit. The MCPF gives an estimate of the losses in terms of resource allocation due to that transfer or subsidy to the firm. In the literature on regulation, it is taken as a parameter and, once estimated, its value is used to determine the optimal power of incentives. In this paper, we assess if the power of incentives could, in turn, influence the actual value of the MCPF.

In practice, none of those two methods for pricing regulated sectors is applied in its purest forms. For example, it can be said that price-cap prevails in the regulation of public utilities in Argentina, but periodic reviews are conducted to move regulated price to levels that guarantee a "fair and reasonable" rate of return, and then the regulatory regime becomes similar to a cost-plus. Also, in most regulated sectors, costs are discriminated between those that are under control of the firm or beyond it. Some taxes are allowed to be passed to prices, but that is not the general case, and it can be argued that in many cases they change relative prices and a very accurate vision is required to pass-through all of them instantaneously to capped prices without a general equilibrium evaluation.

How do we represent those alternative regulatory regimes in our model? ${ }^{9}$ The regulated sectors receive no special treatment regarding their production technology. The difference with the rest of the sectors lies in the way in which the price of the product is defined and the treatment of the service obligation. In fact, we take advantage of the service obligation restriction to avoid the problem of rationing. ${ }^{10}$ Under service obligation, the firm must satisfy all of the demand; depending on the case, it has two alternatives: (1) producing more with the available technology and capital stock but adding other factors (like labor), and absorbing the difference between the fixed price and the average cost; or (2) using an alternative technology with constant returns to scale that allows an increase in the capital stock with an average cost that is similar to the fixed price.

In the first case, as a consequence of the service obligation restriction, the firm can have a loss. In that case, a (negative) tax on the firm's shareholders resolves the problem of the analytical formulation without violating the zero profit condition. If, instead, the demand level falls below the level that would support the regulated price, the model computes an ad-valorem tax on the (Walrasian) price that the shareholders receive; the objective is reached if the price $\left(p_{R}^{l}\right)$ plus tax $t$ gives the fixed price $P$ (Figure 1). When regulation is by cost-plus, the tax (to or from the shareholders) helps to maintain the "fair and reasonable" rate of return. Summarizing, the tax rate is determined as another endogenous variable according to one of the following conditions: (1) the real price for the firm is kept constant, or (2) the real rate of return

9 This discussion is based on Chisari, Estache and Romero (1999) and Chisari, Estache and Romero (2007).

10 The concept of universal service is more demanding; the price must be low enough so that the target population can take advantage of the service. The price is not passive under service obligation. 


\section{FIGURE 1}

PRICE-CAP REGULATION

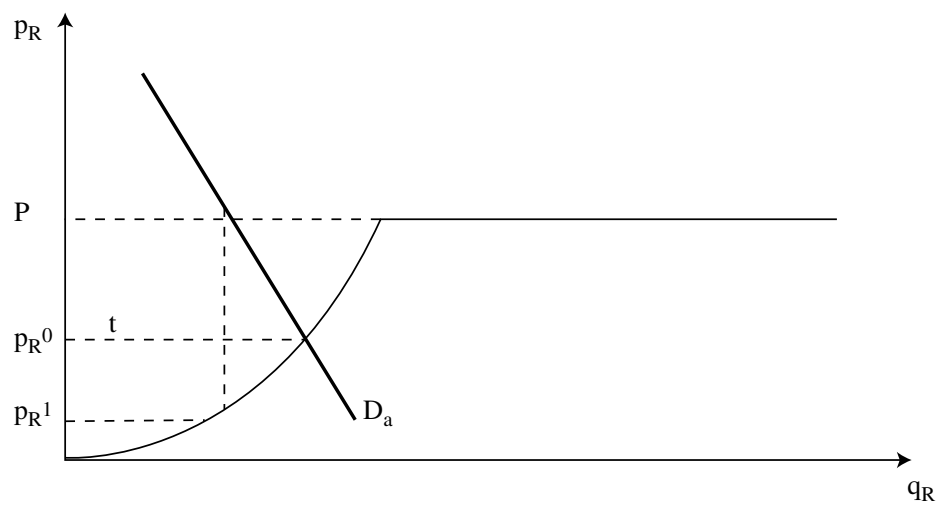

for the firm is kept constant. Notice that in the case of a price-cap regulatory regime, the return to the installed capital will adjust until profits are exhausted. ${ }^{11}$

We should also keep in mind that this way of representing the regulatory regimes has analogies with an endogenous determination of a tax rate, whose recipient is at times the public sector, and at times the firm's shareholders. We can rely therefore on the already available proofs of existence of a general equilibrium with taxes. ${ }^{12}$

\section{THE CGE MODEL}

To estimate the MCPF, we implement a static small open economy CGE model for Argentina. ${ }^{13}$ In order to calibrate our CGE model, we built a 2004 SAM for Argentina; see Table 2 for an aggregated SAM. ${ }^{14}$ The economic activity is disaggregated in 29 sectors. For these sectors, output is exported or sold domestically, competing with imports (Armington, 1969). The SAM identifies three types of labor: formal salaried workers, informal salaried workers, and non-salaried workers. The

11 The question remains whether the firm would not prefer a value below $P$. For the range of the accepted parameters in our model and for the magnitude of the shocks considered, the price-cap was always operative.

12 Shoven and Whalley (1973) provide a demonstration, while Ginsburgh and Keyzer (1997) present a summary of the literature.

13 The model is based on Chisari et al. (2009).

14 As our starting point to build the SAM we used the 1997 (latest available) input-ouput tables constructed by the National Institute of Statistics and Censuses (INDEC, 2001), combined with more recent information from official sources and our own estimates. A full description of the SAM building process can be requested from the authors. 
TABLE 2

AGGREGATED SAM ARGENTINA 2004

(in billions of pesos)

\begin{tabular}{|c|c|c|c|c|c|c|c|c|c|}
\hline & act & com & lab & cap & hhd & gov & row & $s-i$ & total \\
\hline $\begin{array}{l}\text { act } \\
\text { com }\end{array}$ & 352 & 772 & & & 257 & 50 & 115 & 63 & $\begin{array}{l}772 \\
836\end{array}$ \\
\hline $\begin{array}{l}\text { lab } \\
\text { cap }\end{array}$ & $\begin{array}{r}91 \\
248\end{array}$ & & & & & & & & $\begin{array}{r}91 \\
248\end{array}$ \\
\hline $\begin{array}{l}\text { hhd } \\
\text { gov } \\
\text { row }\end{array}$ & $\begin{array}{l}37 \\
44\end{array}$ & 64 & 91 & $\begin{array}{r}223 \\
25\end{array}$ & $\begin{array}{l}14 \\
18\end{array}$ & 60 & & $\begin{array}{r}5 \\
20\end{array}$ & $\begin{array}{l}373 \\
120 \\
108\end{array}$ \\
\hline s-i & & & & & 84 & 11 & -8 & & 88 \\
\hline total & 772 & 836 & 91 & 248 & 373 & 120 & 108 & 88 & \\
\hline
\end{tabular}

Source: SAM Argentina 2004.

remaining productive factor is physical capital. The institutional accounts include the government, a household (i.e, the private domestic institution), and the rest of the world. Tax accounts were disaggregated into eight taxes as shown in Table $3 .{ }^{15}$ There is one private investment account and one public investment account. Sectors such as Electricity, gas and water, Transport, and Communications are subject to a regulatory regime; together, they represent about $10.5 \%$ of total value added (see Table 4 ). The modeling of the labor market allows for unemployment due to the existence of a downward rigid real wage.

Among the primary factors of production, labor is mobile between sectors while capital is sector-specific. The model distinguishes the following four uses for domestic production: intermediate (firms), final (households and government), investment (private and public), and exports (rest of the world). This differentiation allows us to take into account the functioning of the Argentine tax system. Specifically, we model the value added tax avoiding the cascading effect on intermediate transactions. Each household has a nested CES utility function defined over consumption of commodities and leisure - indicating that labor supply is endogenous. The institutional savings can be used for purchasing a capital good (i.e., real investment), or bonds (i.e., financial investment).

In order to compute the MCPF we assume that government consumption and savings are fixed in real terms and, consequently, any change in tax revenue is transferred to households as a lump sum.

15 Notice that in the model, some of these taxes are aggregated into an indirect tax. 
TABLE 3

TAX REVENUE ARGENTINA 2004

\begin{tabular}{|lrrr|}
\hline \multirow{3}{*}{ Tax instrument } & \multicolumn{3}{c|}{ Tax revenue } \\
\cline { 2 - 4 } & billion \$ & \% total & \% GDP \\
\hline Value added & 24.88 & 20.7 & 5.7 \\
Turnover & 11.56 & 9.6 & 2.7 \\
Labor & 16.27 & 13.5 & 3.8 \\
Capital & 19.24 & 16.0 & 4.4 \\
Income & 11.41 & 9.5 & 2.6 \\
Tariffs & 3.17 & 2.6 & 0.7 \\
Exports & 8.71 & 7.2 & 2.0 \\
Other indirect & 19.06 & 15.8 & 4.4 \\
\hline Total & 114.29 & 94.9 & 26.4 \\
\hline
\end{tabular}

Source: SAM Argentina 2004.

TABLE 4

SECTORAL SHARE IN TOTAL VALUE ADDED AND ITS COMPONENTS (IN \%)

\begin{tabular}{|lrrcrrr|}
\hline \multirow{2}{*}{ Sector } & \multicolumn{3}{c}{ Labor } & & \\
\cline { 2 - 4 } & Formal & Informal & Non-wage & & Capital & Value added \\
\hline Non-regulated & 90.8 & 88.6 & 90.8 & & 89.0 & 89.5 \\
Regulated & 9.2 & 11.4 & 9.2 & & 11.0 & 10.5 \\
$\quad$ Electricity, gas and water & 2.4 & 0.0 & 2.4 & 1.7 & 1.7 \\
Transport & 4.4 & 11.4 & 4.4 & 6.2 & 6.2 \\
Communications & 2.4 & 0.0 & 2.4 & 3.1 & 2.6 \\
\hline Total & 100.0 & 100.0 & 100.0 & 100.0 & 100.0 \\
\hline
\end{tabular}

Source: SAM Argentina 2004.

\section{THE COMPUTATION OF MCPF FOR ARGENTINA}

In order to compute the MCPF, we assume that the government keeps its expenses in commodities, bonds (issued by the households and the rest of the world), and physical investment constant. Therefore, as mentioned above, the additional tax revenue is redistributed to the households as a lump-sum transfer.

In all simulations we will assume that the marginal revenue is collected by increasing tax rates by $10 \%$. We compute the MCPF associated with different tax instruments using the following formula: 


$$
M C P F=-\left[\frac{\sum_{h} E V_{h}-\left(T R E V-T R E V^{0}\right)}{T R E V-T R E V^{0}}\right]
$$

where EV is the equivalent variation and TREV0 (TREV) is the initial (counterfactual) tax revenue. The value of the additional tax revenue is subtracted from the change in welfare because the MCPF measures the cost of taxation and not the benefit of public spending. We compute the MCPF under different assumptions in the following experiments:

- Experiment 1 (E1). In this simulation we assume full employment, a high labor supply elasticity (estimated at 0.25 ), and that all regulated sectors (i.e., Electricity, gas and water, Transport and Communications) are subject to the incremental tax rate. Regulated prices are fixed in terms of foreign currency (i.e., see variable WFSTAR in the Appendix). This is our base simulation; in simulations 2-8 we test the sensitivity of our results to different assumptions.

- Experiment 2 (E2-unemp). This is similar to E1 under the assumption that the existence of unemployment is due to a downward rigid real wage rate (i.e., in terms of the consumer price index).

- Experiment 3 (E3-exclu). In this simulation some sectors are excluded from the increase in tax rates. This simulation is motivated by the existence of sectors with different degrees of formality or that are untaxed because of economic policy or social reasons. We considered two variants of this experiment. In alternative 1, the excluded sectors are the Food industry, beverages and tobacco, Education, and Health. In alternative 2, the excluded sectors are the regulated sectors.

- Experiment 4 (E4-regul). The number of regulated sectors is increased. We assume that the regulated sectors are Electricity, gas and water, Transport, Communications, Food industry, beverages and tobacco, Education, and Health.

- Experiment 5 (E5-elas). The elasticity of labor supply is decreased to 0.10. This experiment tests the sensitivity of our results to the value of a key parameter in the computation of deadweight losses.

- Experiment 6 (E6-cpi). In this case regulated prices are indexed to the retail price index (i.e., see variable CPI in the Appendix).

- $\quad$ Experiment 7 (E7-mobcap). We assume that $40 \%$ of the capital factor is perfectly mobile between sectors. The objective is to compare a long-run versus a shortrun situation. Notice that, in this scenario, the tax on capital is paid by specific as well as mobile capital.

- Experiment 8 (E8-rowcap). $40 \%$ of the capital factor is internationally mobile. We assess how the MCPF will change if capital can leave the domestic country when taxes are increased. The tax is paid by both types of capital.

Table 5 compares the calculation of the MCPF of the following five taxes included in the model: turnover, on labor, on capital, value added, and income. The MCPF of 


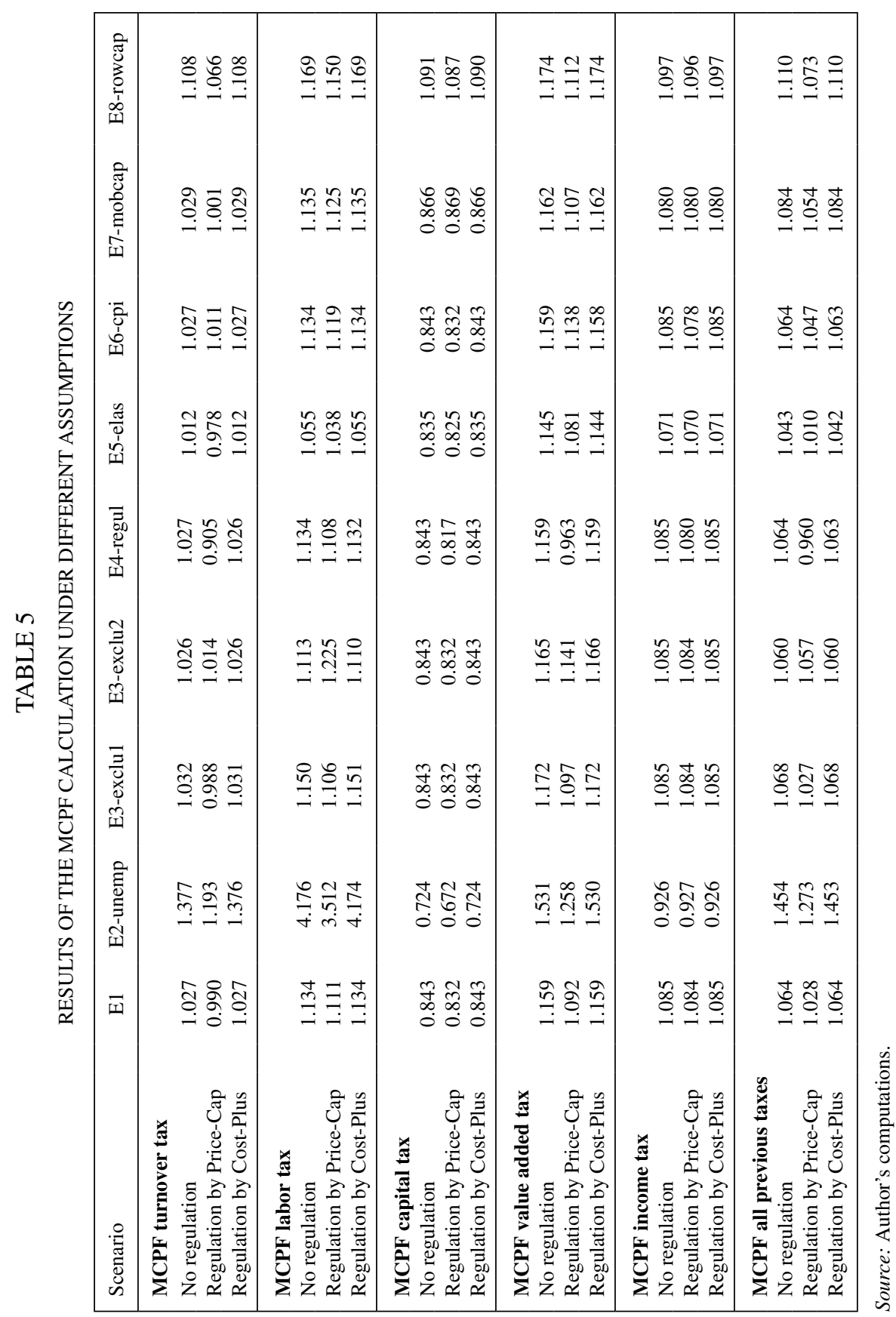


each tax is computed under three different scenarios: (i) no regulation; (ii) regulation by price-cap; and (iii) regulation by cost-plus.

It can be seen that our estimates for the MCPF are in the range of those found in the literature. We can also say that the results show sensitivity to the elasticities of factor supply, the relative size of the regulated sector, the distortion generated by the regulatory regime in the commodity markets, and the presence or absence of foreign shareholders (i.e., international capital mobility).

We can summarize the results as follows.

1. The MCPF moves in the range of 0.67 to 1.50 , depending on the type of tax used to increase the revenue of the government, and the assumption on price regulation. The only exception is the case of taxes on labor under unemployment; in that case, the loss of jobs increases the MCPF beyond the expected range.

2. There are differences in the estimated level of the MCPF for alternative regulatory regimes. Let us focus our attention first on experiment E1, the base case. Price-Cap regulation will reduce deadweight losses with respect to a costplus regime. The results show, for example, that collecting one additional peso by increasing the value added tax will produce a welfare loss equivalent to 16 cents when no sectors are regulated. Instead, when sectors such as Electricity, gas and water, Transport, and Communications are regulated by a price-cap mechanism, the MCPF will be decreased to 9 cents (see E1 for Value Added Tax). The MCPF varies with the regulatory regime but the bias is always in terms of reducing its level in the case of price-cap. In fact, the most important (absolute) difference with respect to the no regulation scenario is observed for the price-cap regulatory regime. This result can be explained by the fact that, under cost-plus, capital owners do not absorb the burden of taxes, and this creates a higher cost in terms of distortions. On the contrary, when the regulation is by price-cap, the markets for goods are more isolated from the price increases due to increases in taxes. However, it could be expected that additional costs due to tax increases would be passed through to (regulated) prices and actual results would be similar to the cost-plus case. Of course, these estimates have to be reconsidered in long-run scenarios. It is not realistic to expect that tax increases will not be passed through to prices; however, final changes in relative prices and in costs of regulated firms could be difficult to calculate. Therefore, it can be expected that the actual result will be something between the extreme cases of price-cap and cost-plus.

3. The presence of exempted sectors increases the MCPF and the estimated differences between regulatory regimes. It can be observed that when some sectors are excluded from the increase in the tax rates, the differences between the MCPF with and without regulation are magnified. However, the differences of the MCPF between regimes also depend on the presence of already existing distortions and special treatments.

4. Those differences are more noticeable when regulated sectors are larger with respect to the rest of the economy. It is interesting to see, in Experiment 4 (E4- 
regul), that an increase in the number of sectors subject to regulation also increases the differences in the results by regulatory regime - compare scenarios E4 and E1. Therefore, the relative size of the economic sectors subject to regulation is relevant to our results.

5. The existence of unemployment increases the MCPF. Unemployment implies that the loss of jobs is very costly for aggregated welfare. If additional taxes increase prices, our assumption is that nominal wages will grow to keep real wages constant, and this creates more unemployment. The results depend then on the assumption of wage indexation when markets are out of equilibrium.

6. The MCPF is lower when revenue is obtained through several taxes simultaneously instead of with only one tax. Notice also (last rows) that when several taxes are increased simultaneously the MCPF is lower than the MCPF for some of them, like the VAT. This result coincides with the findings of Warlters and Auriol (2005) and seems to be a "second best effect"; that is, there are distortions that are cancelled among themselves.

7. MCPF is lower if labor supply is more inelastic. As expected, the reduction of the elasticity of labor supply reduces the magnitude of the distortions and therefore the MCPF level (see E5-elas). If we recall Feldstein (1997), one of the reasons for the existence of distortions is the assumption of positive labor supply elasticity. Taxes impact on the relative price of goods and leisure and create a deadweight loss.

8. The MCPF increases when capital can move between sectors. As can be seen by comparing the base simulation (E1) and experiment E7-mobcap, the MCPF increases when part of the capital factor can move freely between sectors after increasing the tax rates.

9. The MCPF will be lower (or even negative) under price-cap when capital is internationally mobile. And this calls attention to the sensitivity of results to the (external) closure rule of the model (i.e., if the economy is open to trade and capital movements or not). In the case of Argentina, some taxes show a negative MCPF (i.e., benefit), as can be seen for the case of taxation of capital income. This is not the first time it is observed (see also Warlters and Auriol (2005)), and it is explained by the fact that part of the tax burden is passed-through to foreign owners of capital. Clearly, this marginal benefit is unsustainable in a long run situation with full capital mobility. ${ }^{16}$ This is confirmed in experiment E8-rowcap: when a certain proportion of

16 One finding that Chisari et al. (2003) obtained with a similar model is that differences exist in the performance required of the trade balance depending on the regulatory regime of the tariffs. If a firm is to achieve internal efficiency yields, for example, the price-cap regulation generates benefits that must eventually return the invested capital. It is highly probable that part of these dividends are legally transferred, as is their right, to the foreign owners or simply used to purchase foreign assets -a question of preference- even if the owners of the benefits are local. This must place greater pressure on the trade 
the capital is mobile between countries, the observed differences between regimes tend to be reduced. It is already known that domestic authorities could favor one regime or the other, and the corresponding power of incentives, depending on the share of foreign agents in total capital of regulated sectors. What our result shows is that the MCPF itself might depend on that share. Consistently, the effort of the economy (in terms of exports with respect to GDP) must be lower under price-cap than under cost-plus, when there are tax increases; this is captured in the simulations because there is a lower transfer of dividends abroad.

We also tested the sensitivity of our results to the increase in the tax rates (50\% instead of 10\%) and to the value of Armington elasticities (i.e., the degree of substitutability between domestic and imported goods). As expected, as we increase the nominal tax rate, the MCPF is also increased, suggesting that the marginal cost is higher than the average cost. And we can see that an increase in Armington elasticities also increases the MCPF, since consumers are more able to substitute their domestic consumption basket for imported goods.

\section{CONCLUDING REMARKS}

In this paper we have estimated the MCPF for Argentina using a computable general equilibrium model calibrated with a Social Accounting Matrix as of 2004. The estimates obtained are in the range of the results found in the literature for other countries. Moreover, we find that the MCPF is sensitive to the type of price regulation used for industries under regulatory supervision. However, the cost-plus regulatory regime tends to mimic the results of the no regulation case, under a great variety of simulation and cases.

The presence of a price-cap modifies the capacity of passing through additional costs to consumers, and creates implicit transfers from shareholders to consumers when relative prices change against the regulated price. The result is that in most cases the MCPF is lower under price-cap than under cost-plus or under no regulation. One important implication is that public projects will be approved more easily in countries where price-cap regulatory regimes prevail and are used more frequently. Under pricecap there is a reason for being light handed when subsidies are granted, since the cost of obtaining the fiscal resources is reduced as regards a similar economy that regulates via cost-plus. The effect is even more important when shareholders reside in the rest of the world and their welfare is not fully accounted for in social welfare. The last

balance than a rate of return regulation, according to which the tariff would drop together with a drop in costs. The effect is not generally considered among the elements evaluated when deciding whether to opt for price-cap or cost-plus; what is considered is the problem of distortions arising from the taxes used to subsidize inefficient enterprises. The latter tends to favor the price cap; instead, the impact on the trade balance offers a convincing argument for the cost plus. There is an expected efficiency loss because cost plus does not control opportunism; this loss in efficiency could force up the level of imports if the input is not produced domestically. Note that we are comparing both possibilities. 
result is due to the fact that international transfers (i.e., dividends) put the trade balance under stress and are more demanding on the efforts of the economy to export.

Our results also show that differences in MCPF are larger when price regulations are used on a wider portion of the economy. Less developed economies are prone to use price controls as an instrument of economic policy, even in the form of threats and even on activities open to competition. Therefore, in those economies the share of sectors under regulation in total GDP can be substantial and, consequently, have a greater impact on MCPF.

Finally, we find that the MCPF depends on the type of tax used to collect revenue. For the case of Argentina, the VAT has a much higher MCPF than other taxes, like the sales tax, which are traditionally reckoned as more costly in terms of inefficiencies in the allocation of resources. The reason lies in the large differences that exist in the treatment of some sectors, and in the abundance of exemptions and special regimes.

\section{REFERENCES}

ARMINGTON, P. S. (1969). "A Theory of Demand for Products Distinguished by Place of Production", International Monetary Fund Staff Papers 16, pp. 159-178.

ATKINSON, A. B. and N. H. STERN (1974). "Pigou, Taxation and Public Goods", The Review of Economic Studies 41 (1), pp. 119-128.

BALLARD, L. C. and D. FULLERTON (1992). "Distortionary Taxes and the Provision of Public Goods", The Journal of Economic Perspectives 6 (3), pp. 117-131.

BRETON, A. (1996). Competitive Government. Cambridge University Press.

BROWNING, E. K. (1976). "The Marginal Cost of Public Funds", Journal of Political Economy 84 (2), pp. 283-298.

BROWNING, E. K. (1987). "On the Marginal Welfare Cost of Taxation”, The American Economic Review 77 (1), pp. 11-23.

CHISARI O. O., C. ROMERO, G. FERRO, R. THELLER, M. CICOWIEZ, J. FERRARO, M. GONZALEZ, A. BLANCO y J. MAQUIEYRA (2009). Un Modelo de Equilibrio General Computable para la Argentina. PNUD-Argentina.

CHISARI O. O., A. ESTACHE and C. ROMERO (1999). "Winners and Losers of Utility Privatization and Regulation in Argentina", The World Bank Economic Review 13 (2), pp. 357-378.

CHISARI O. O., A. ESTACHE and C. ROMERO (2007). "Lessons from Computable General Equilibrium Models Applied to Regulatory Economics", in O. O. Chisari, Regulatory Economics and Quantitative Methods, London: Edward Elgar.

CHISARI, O. O., A. ESTACHE, G. LAMBARDI and C. ROMERO (2003). "Trade Performance and Regulatory Regimes", Meeting of Asociación Argentina de Economía Política and LACEA (Puebla).

DESAI M. A. and M. DHARMAPALA (2004). "Corporate Tax Avoidance and High Powered Incentives", NBER Working Paper 10471.

FELDSTEIN, M. (1997). "How Big Should the Government Be?”, NBER Working Paper 5868.

GINSBURGH, V. and M. KEYZER (1997). The Structure of Applied General Equilibrium Models, Cambridge: MIT Press.

HARBERGER, A. (1962), "The Incidence of the Corporation Income Tax", Journal of Political Economy 70 (3), pp. 215-240.

LAFFONT, J. J. and J. TIROLE (1993). A Theory of Incentives in Procurement and Regulation, Cambridge: MIT Press.

MUSGRAVE, R.A.(1959). The Theory of Public Finance, New York, McGraw-Hill.

PIGOU, A. (1928). A Study in Public Finance. London: Macmillan. 
SHOVEN, J. B. and J. WHALLEY (1973). "A General Equilibrium Calculation of the Effects of Differential Taxation of Income from Capital in the U. S.", Journal of Public Economics 1 (3-4): pp. 281-321. STIGLITZ, J. E. (2000). Economics of Public Sector, New York: W. W. Norton.

STIGLITZ, J. E. and P. S. DASGUPTA (1971). "Differential Taxation, Public Goods, and Economic Efficiency", The Review of Economic Studies 38 (2), pp. 151-174.

USHER, D. (1991). "The Hidden Cost of Public Expenditure", in R. Bird, More Taxing than Taxes?, ICS Press.

WARLTERS, M. and E. AURIOL (2005). "The Marginal Cost of Public Funds in Africa", The World Bank Policy Research Working Paper 3679. 


\section{APPENDIX}

\section{THE CGE MODEL}

This Appendix presents the CGE model mathematical statement. The following notation is used: upper case letters for endogenous variables, lower case letters for exogenous variables, and Greek letters stand for behavioral parameters. When a variable name is followed by zero, it refers to an initial value (i.e., reported by the SAM). The following indexes are used: $\mathrm{s}$ for goods or sectors (each sector produces only one good), $\mathrm{f}$ for factors, $\mathrm{b}$ for bonds, $\mathrm{i}$ for institutions, and $\mathrm{h}$ for households. Quantity (respectively price) variables are identified with an initial Q (respectively $\mathrm{P}$ for Price variables).

\section{VARIABLES}

\section{Quantities}

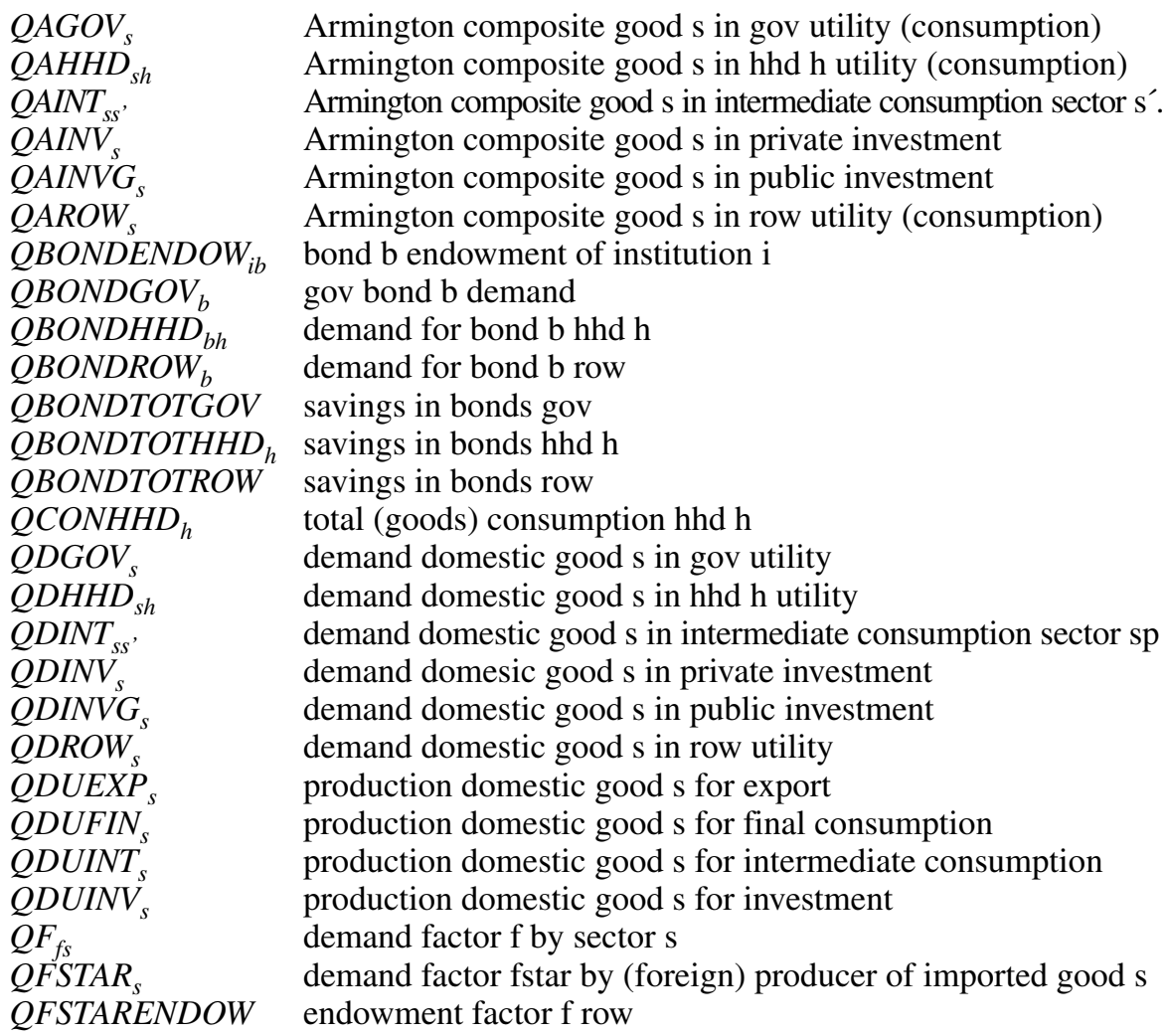




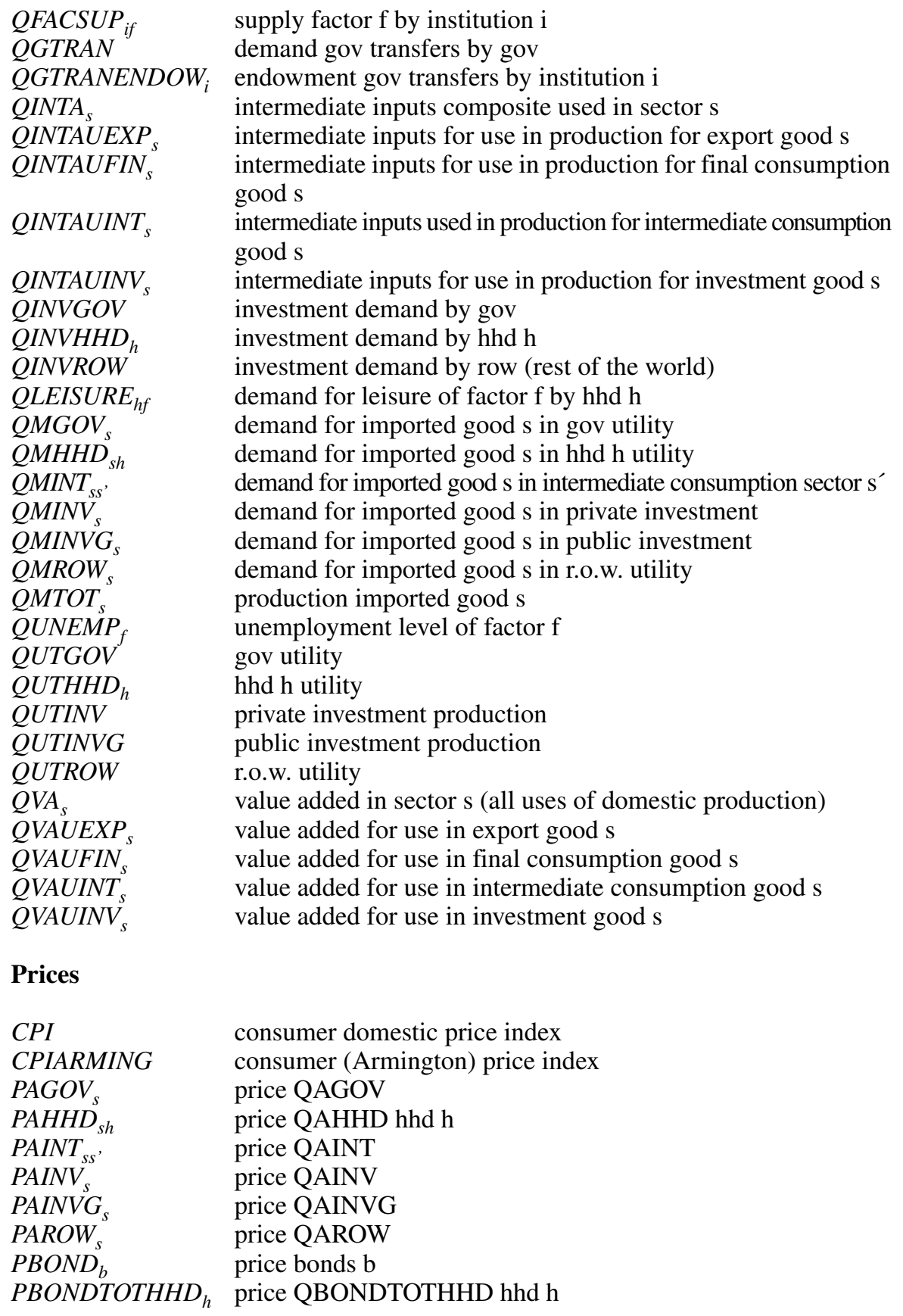




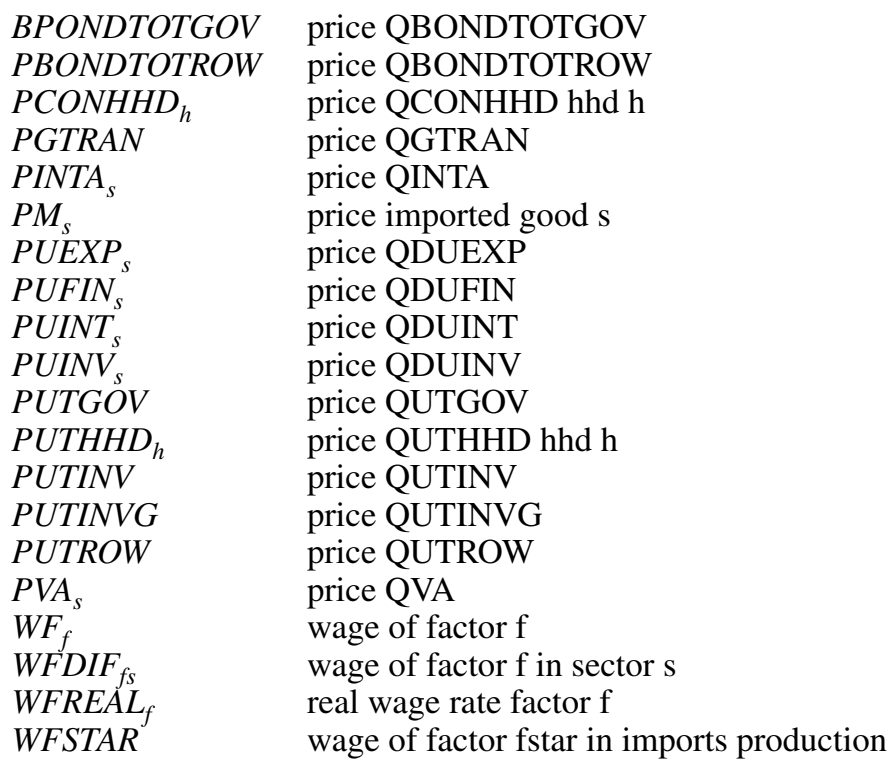

\section{Incomes}

YGOV income gov

$Y_{H H D} \quad$ income hhd h

YROW income row

Tax revenue

TREV tax revenue

\section{Rate of unemployment}

$U_{f} \quad$ rate of unemployment of factor $\mathrm{f}$

\section{Regulatory regimes (equivalent taxes)}

$R E G F_{f s} \quad$ ad-valorem tax used to regulate wage factor $\mathrm{f}$ (cost-plus)

REGAUINT $\quad$ a-v.t. used to regulate price good s for intermediate consumption (price-cap)

REGAUFIN $_{s} \quad$ a-v.t. used to regulate price good s for final consumption (pricecap)

$R E G A U I N V_{s} \quad$ a-v.t. used to regulate price of good s for investment (price-cap) $R_{E G A U E X P_{s}} \quad$ a-v.t. used to regulate price of good s for export (price-cap) TRANREGF a-v.t. transfer (implicit tax collection) due to regulation to wage of factor $\mathrm{f}$ (cost-plus) 
TRANGERA

PUINTREAL PUFINREAL PUINVREAL PUEXPREAL WFDIFREAL $L_{s}$ PUINTWFSTAR $_{S}$

PUFINWFSTAR $_{S}$

PUINVWFSTAR $_{S}$ PUEXPWFSTAR $_{S}$ WFDIFWFSTAR a-v.t. transfer (implicit tax collection) due to regulation to price of good s (price-cap) real price of good $\mathrm{s}$ for intermediate consumption real price of good s for final consumption real price of good s for investment real price of good s for export real wage of factor $f$ in sector $s$ real price of good $\mathrm{s}$ for intermediate consumption in terms of WFSTAR real price of good s for final consumption in terms of WFSTAR real price of good s for investment in terms of WFSTAR real price of good s for export in terms of WFSTAR real wage of factor $f$ in sector $s$ in terms of WFSTAR

\section{Closure rule for government}

FIXGBOND if flex QGBONDTOTGOV is fixed

FIXGCON if flex QUTGOV is fixed

FIXGINV if flex QINVGOV is fixed

\section{Closure rule for r.o.w.}

FIXBONDROW if flex QBONDROW is fixed

\section{EQUATIONS}

\section{Value added block}

Equations (1) and (2) are the first order conditions (FOC) in the firm cost minimization problem for mobile and specific factors, respectively. Equation (3) is the Cobb-Douglas value added production function. The parameter chgtec(f,s) can be used to model a factor-specific technical change in a particular sector.

$$
\begin{gathered}
W F_{f}\left(1+t f_{f s}+R E G F_{f s}\right) Q F_{f s}=\alpha_{f s}^{V A} P V A_{s} Q V A_{s} f \in \text { fmovil } \\
W F D I F_{f s}\left(1+t f_{f s}+R E G F_{f s}\right) Q F_{f s}=\alpha_{f s}^{V A} P V A_{s} Q V A_{s} f \in \text { fespec } \\
Q V A_{s}=\beta_{s}^{V A} \prod_{f}\left(\operatorname{chgtec}_{f s} Q F_{f s}\right)^{\alpha_{f s}^{V A}}
\end{gathered}
$$




\section{Intermediate inputs block}

Equations (4) and (5) are the FOC for the intermediate input demand. Equations (6) to (9) refer to the choice between domestic and imported intermediate inputs following the usual assumption of product differentiation according to their country of origin (Armington, 1969). A CES function is used to model imperfect substitutability between imports and domestic commodities (equation (6)). ${ }^{17-18}$ Equation (7) shows the tangency condition that determines the optimal mix between domestic and imported commodities. Equation (9) computes the supply price of the composite commodity as a weighted average of the domestic and imported prices. In equations (7) and (9) tmuint is the tariff faced by firms.

When $Q M I N T_{s^{\prime} s}^{0}>0$ and $Q D I N T_{s^{\prime} s}^{0}>0$, the model includes equations (6) and (7). Alternatively, if $Q M I N T_{s^{\prime} s}^{0}=0$ or $Q D I N T_{s^{\prime} s}^{0}=0$, the model includes equation (8).

$$
\begin{aligned}
& Q^{\prime} A I N T_{s s^{\prime}}=i o_{s s^{\prime}} Q I_{N T A_{s^{\prime}}} \\
& \text { PINTA }_{s} \text { IINTA }_{s}=\sum_{s^{\prime}} \text { PAINT }_{s^{\prime} s} \text { QAINT }_{s^{\prime} s} \\
& Q A I N T_{s^{\prime} s}=\phi_{s^{\prime} s}^{I N T}\left(\delta_{s^{\prime} s}^{M I N T} Q M I N T_{s^{\prime} s}^{-\rho_{s}^{\prime \prime s}}+\delta_{s^{\prime} s}^{D I N T} Q D I N T_{s^{\prime} s}^{-\rho_{s}^{M I N T}}\right)^{-\frac{1}{\rho_{s}^{M I N T}}} \\
& \frac{Q M I N T_{s^{\prime} s}}{Q D I N T_{s^{\prime} s}}=\left(\frac{\text { PUINT }_{s^{\prime}}}{P M_{s^{\prime}}\left(1+\text { tmint }_{s^{\prime} s}+\text { tivamint }_{s^{\prime} s}\right)} \frac{\delta_{s^{\prime} s}^{M I N T}}{\delta_{s^{\prime} s}^{D I N T}}\right)^{\frac{1}{1+\rho_{s^{\prime} s}^{M I N T}}} \\
& Q A I N T_{s^{\prime} s}=Q M I N T_{s^{\prime} s}+Q D I N T_{s^{\prime} s} \\
& \text { PAINT }_{s^{\prime} s} Q^{\prime} \text { IINT }_{s^{\prime} s}=P M_{s^{\prime}}\left(1+\text { tmint }_{s^{\prime} s}\right) Q M I N T_{s^{\prime} s}+P^{\prime} \text { IINT }_{s^{\prime}} Q D I N T_{s^{\prime} s}
\end{aligned}
$$

\section{Intermediate use block}

Domestic production for intermediate consumption is a Leontief (i.e., fixed coefficients) function of the quantities of value added (equation (10)) and an aggregate intermediate input (equation (11)). ${ }^{19}$ The price of value added is calculated, implicitly, in equation (12); the rest of the variables are determined elsewhere in the model. The taxes faced by the domestic production for intermediate consumption are (1) the

17 Additionally, the choice between domestic and imported varieties of the same good for intermediate consumption can be made according to a Leontief function.

18 The substitution elasticity between domestic commodities and imports is $\sigma_{c}=1 /\left(\rho q_{c}-1\right)$.

19 Notice that the aggregate intermediate input used in all uses of the domestic production is "produced" in equation (4). 
activity tax (rate tauint), (2) the turnover tax (rate tiibbuint), and (3) the value added tax (usually, rate tivauint is zero).

$$
\begin{gathered}
\text { QVAUINT } \text { s }_{s} \text { ivauint }_{s} \text { QDUINT } \\
\text { QINTAUINT } \text { intuint }_{s} \text { QDUINT } \\
\text { PUINT }_{s}\left(1-\text { tauint }_{s}-\text { tiibbuint }_{s}-\text { REGAUINT }_{s}\right) Q D U I N T_{s}= \\
\text { PVA }_{s}\left(1+\text { tivauint }_{s}\right) Q V A U I N T_{s}+\text { PINTA }_{s} \text { QINTAUINT }_{s}
\end{gathered}
$$

\section{Final consumption block}

Domestic production for final consumption (i.e., households and government) is also a Leontief function of value added (equation (13)) and an aggregate intermediate input (equation (14)). The price of value added in the production for final consumption is computed in equation (15).

$$
\begin{gathered}
\text { QVAUFIN }_{s}=\text { ivaufin }_{s} \text { QDUFIN }_{s} \\
\text { QINTAUFIN }_{s}=\text { intufin }_{s} Q D U F I N_{s} \\
\text { PUFIN }_{s}\left(1-\text { taufin }_{s}-\text { tiibbufin }_{s}-\text { REGAUFIN }_{s}\right) \text { QDUFIN }_{s}= \\
\text { PVA }_{s}\left(1+\text { tivaufin }_{s}\right) Q \text { QVAUFIN }_{s}+\text { PINTA }_{s} \text { QINTAUFIN }_{s}
\end{gathered}
$$

\section{Investment use block}

Domestic production for public and private investment is also a fixed coefficients function of value added (equation (16)) and an aggregate intermediate input (equation (17)). The price of value added in the production for investment is computed in equation (18).

$$
\begin{gathered}
\text { QVAUINV } \text { s ivauinv }_{s} Q D U I N V_{s} \\
\text { QINTAUINV } \text { intuinv }_{s} Q D U I N V_{s} \\
\text { PUINV }_{s}\left(1-\text { tauinv }_{s}-\text { tiibbuinv }_{s}-\text { REGAUINV }_{s}\right) Q D U I N V_{s}= \\
\text { PVA }_{s}\left(1+\text { tivauinv }_{s}\right) Q V A U I N V_{s}+\text { PINTA }_{s} \text { QINTAUINV }_{s}
\end{gathered}
$$




\section{Export use block}

Domestic production for export is also a Leontief function of value added (equation (19)) and an aggregate intermediate input (equation (20)). The price of value added in the production for export is computed in equation (21). In this case, the activity tax corresponds to the export tax.

$$
\begin{gathered}
\text { QVAUEXP } P_{s}=\text { ivauexp }_{s} Q D U E X P_{s} \\
\text { QINTAUEXP } P_{s}=\text { intuexp }_{s} Q D U E X P_{s} \\
\operatorname{PUEXP}_{s}\left(1-\text { tauexp }_{s}-\text { tiibbuexp }_{s}-\text { REGAUEXP }_{s}\right) \text { QDUEXP }_{s}= \\
\text { PVA }_{s}\left(1+\text { tivauexp }_{s}\right) Q V A U E X P_{s}+\text { PINTA }_{s} \text { QINTAUEXP }_{s}
\end{gathered}
$$

\section{Imports block}

The rest of the world produces goods demanded by the domestic economy (i.e., imports) and the rest of the world itself by using only one production factor denominated FSTAR. Equation (22) and (23) are the FOC of the cost minimization problem solved by the foreign firms.

$$
\begin{gathered}
\text { WFSTAR }_{s} \text { QFSTAR }_{s}=\text { PM }_{s} \text { QMTOT }_{s} \\
\text { QFSTAR }_{s}=\text { QMTOT }_{s}
\end{gathered}
$$

\section{Household consumption of goods block}

Equations (24) and (25) are the FOC for the cost minimization problem solved by the households in order to "compose" their consumption aggregate according to a Cobb-Douglas utility function The households distinguish between domestic and imported goods according to a CES function (equations (26) to (29)). ${ }^{20}$ Equation (27) is the tangency condition that determines the quantities of domestic and imported commodities consumed by the households. Equation (29) computes the price of the composite Argmington good demanded by household $\mathrm{h}$ as a weighted average of the domestic and imported prices of the same good. ${ }^{21}$

\footnotetext{
20 Additionally, the model allows using a Cobb-Douglas function to produce the Armington composite good demanded by the households.

21 Notice that the domestic/imported composition of the Armington good is not the same for all the agents in the model.
} 
When $Q M H H D_{s h}^{0}>0$ and $Q D H H D_{s h}^{0}>0$, the model includes equations (26) and (27). On the other hand, if $Q M H H D_{s h}^{0}=0$ or $Q D H H D_{s h}^{0}=0$, the model includes equation (28).

$$
\begin{aligned}
& P A H H D_{s h} Q A H H D_{s h}=\alpha_{s h}^{H H D} P C O N H H D_{h}\left(1-t d_{h}\right) Q C O N H H D_{h} \\
& Q C O N H H D_{h}=\beta_{h}^{H H D} \prod_{s} Q A H H D_{s h}^{\alpha_{s}^{H H D}} \\
& Q A H H D_{s h}=\phi_{s h}^{H H D}\left(\delta_{s h}^{M H H D} Q M H H D_{s h}^{-\rho_{s h}^{H H D}}+\delta_{s h}^{D H H D} Q D H H D_{s h}^{-\rho_{s h}^{H H D}}\right)^{-\frac{1}{\rho_{s h}^{H H D}}} \\
& \frac{Q M H H D_{s h}}{Q D H H D_{s h}}=\left(\frac{\text { PUFIN }_{s}}{P M_{s}\left(1+\text { tmhhd }_{s h}+\text { tivamhhd }_{s h}\right)} \frac{\delta_{s h}^{M H H D}}{\delta_{s h}^{D H H D}}\right)^{\frac{1}{1+\rho_{s h}^{H H D}}} \\
& Q A H H D_{s h}=Q M H H D_{s h}+Q D H H D_{s h} \\
& P A H H D_{s h} Q A H H D_{s h}=P M_{s}\left(1+t^{2} h h d_{s h}+\text { tivamhhd }_{s h}\right) Q M H H D_{s h} \\
& + \text { PUFIN }_{s} Q D H H D_{s h}
\end{aligned}
$$

\section{Labor-leisure choice block}

Equations (30) and (31) are the FOC of the labor (consumption)-leisure choice problem faced by the households; for each factor in flab may exist a leisure demand. Equation (32) defines a Cobb-Douglas utility function over consumption and leisure for household h. ${ }^{22}$ Equation (33) computes the supply of factor flab by household h. Notice that maxhour $_{h, f l a b}$ is the amount of hours of factor flab that hosuehold $\mathrm{h}$ has available.

$$
\begin{aligned}
& \text { PCONHHD }_{h} \text { QCONHHD }_{h}=\alpha_{h}^{C O N S} \text { PUTHHD }_{h} \text { QUTHHD }_{h}
\end{aligned}
$$

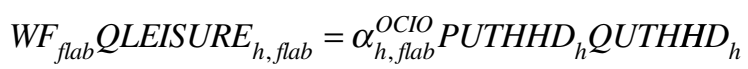

$$
\begin{aligned}
& Q U T H H D_{h}=\alpha_{h}^{U T H H D} Q C O N H H D_{h}^{\alpha_{h}^{C O N}} \prod_{\text {flab }} Q L E I S U R E_{h, \text { flab }}^{\alpha_{h, l a b}^{O C l O}} \\
& \text { QFACSUP }_{h, \text { flab }}=\text { maxhour }_{h, \text { flab }}-Q_{\text {LEISURE }}{ }_{h, \text { flab }}
\end{aligned}
$$

22 Additionally, the model allows using a CES utility function to model the labor-leisure choice. 


\section{Government utility block}

Government utility is "produced" according to a Cobb-Douglas function (equations (34) and (35)). The government also differentiates between domestic and imported goods according to a CES function (equations (36) and (37)). ${ }^{23}$ Equation (38) replaces equations (36) and (37) when the government demands a good from only one origin. ${ }^{24}$ Equation (39) defines the price of the Armington composite good consumed by the government.

When $Q M G O V^{0}>0$ and $Q D G O V^{0}>0$, the model includes equations (37) and (37). Alternatively, if $Q M G O V^{0}=0$ or $Q D G O V^{0}=0$, the model includes equation (38).

$$
\begin{aligned}
& \text { PAGOV } V_{s} Q A G O V_{s}=\alpha_{s}^{G O V} P U T G O V \cdot Q U T G O V \\
& Q U T G O V=\beta^{G O V} \prod_{s} Q A G O V_{s}^{\alpha_{s}^{G O V}} \\
& Q A G O V_{s}=\phi_{s}^{G O V}\left(\delta_{s}^{M G O V} Q M G O V_{s}^{-\rho_{s}^{G O V}}+\delta_{s}^{D G O V} Q D G O V_{s}^{-\rho_{s}^{G O V}}\right)^{-\frac{1}{\rho_{s}^{G O V}}} \\
& \frac{Q M G O V_{s}}{Q D G O V_{s}}=\left(\frac{\operatorname{PUFIN}_{s}}{\text { PM }_{s}\left(1+\text { tmgov }_{s}+\text { tivamgov }_{s}\right)} \frac{\delta_{s}^{M G O V}}{\delta_{s}^{D G O V}}\right)^{\frac{1}{1+\rho_{s}^{G O V}}} \\
& Q A I N V G_{s}=Q M I N V G_{s}+Q D I N V G_{s} \\
& \text { PAGOV }_{s} Q A G O V_{s}=P_{s}\left(1+\text { tmgov }_{s}+\text { tivamgov }_{s}\right) Q M G O V_{s} \\
& + \text { PUFIN }_{s} Q D G O V_{s}
\end{aligned}
$$

\section{Private investment (capital good) production block}

Private investment (i.e., demanded by the households and the rest of the world) is produced by combining the different goods using a Cobb-Douglas production function (equations (40) and (41)). ${ }^{25}$ Also in this case, imperfect substitutability between domestic and imported varieties of the same good is assumed (equations (42) to (45)). ${ }^{26}$ When only one variety of the good is demanded, equations (42) and (43) are replaced by equation (44).

\footnotetext{
23 Additionally, the model allows using a Cobb-Douglas function to produce the Armington composite good demanded by the government.

24 This is the case in the Argentina SAM used to calibrate the model.

25 Additionally, a fixed coefficients function can be used.

26 Alternatively, a Leontief or Cobb-Douglas utility function can be used.
} 


$$
\begin{aligned}
& \text { PAINV }{ }_{s} Q A I N V_{s}=\alpha_{s}^{I N V} \text { PUTINV.QUTINV } \\
& Q U T I N V=\beta^{I N V} \prod_{s} Q A I N V_{s}^{\alpha_{s}^{I N V}} \\
& Q A I N V_{s}=\phi_{s}^{I N V}\left(\delta_{s}^{M I N V} Q M I N V_{s}^{-\rho_{s}^{I N V}}+\delta_{s}^{D I N V} Q D I N V_{s}^{-\rho_{s}^{I N V}}\right)^{-\frac{1}{\rho_{s}^{I N V}}} \\
& \frac{Q M I N V_{s}}{Q D I N V_{s}}=\left(\frac{P U I N V_{s}}{P M_{s}\left(1+\text { tminv }_{s}+\text { tivaminv }_{s}\right)} \frac{\delta_{s}^{M I N V}}{\delta_{s}^{D I N V}}\right)^{\frac{1}{1+\rho_{s}^{I N V}}} \\
& Q A I N V_{s}=\left(1+\text { tminv }_{s}+\text { tivaminv }_{s}\right) Q M I N V_{s}+Q D I N V_{s} \\
& \text { PAINV }_{s} \text { QAINV }_{s}=P M_{s}\left(1+\text { tminv }_{s}+\text { tivaminv }_{s}\right) Q M I N V_{s} \\
& +P U I N V_{s} Q D I N V_{s}
\end{aligned}
$$

\section{Public investment (capital good) production block}

Public investment is modeled similarly to the private investment (equations (46) to (51)). When a good is only domestic or imported, equations (48) and (49) are replaced by equation (50).

$$
\begin{aligned}
& P A I N V G_{s} Q A I N V G_{s}=\alpha_{s}^{I N V G} P U T I N V G . Q U T I N V G \\
& Q U T I N V G=\beta^{I N V G} \prod_{s} Q A I N V G_{s}^{\alpha_{s}^{I N V G}} \\
& Q A I N V G_{s}=\phi_{s}^{I N V G}\left(\delta_{s}^{M I N V G} Q M I N V G_{s}^{-\rho_{s}^{I N V} G}+\delta_{s}^{D I N V} Q D I N V G_{s}^{-\rho_{s}^{I N V G}}\right)^{-\frac{1}{\rho_{s}^{I N V G}}} \\
& \frac{Q M I N V G_{s}}{Q D I N V G_{s}}=\left(\frac{P U I N V_{s}}{P M_{s}\left(1+\text { tminvg }_{s}\left(1+\text { tivaminvg }_{s}\right)\right)} \frac{\delta_{s}^{M I N V G}}{\delta_{s}^{D I N V G}}\right)^{\frac{1}{1+\rho_{s}^{I N V G}}} \\
& Q A I N V G_{s}=Q M I N V G_{s}+Q D I N V G_{s} \\
& \text { PAINVG }_{s} \text { QAINVG }_{s}=P M_{s}\left(1+\text { tminvg }_{s}+\text { tivaminvg }_{s}\right) Q M I N V G_{s} \\
& +P U I N V_{s} Q D I N V G_{s}
\end{aligned}
$$




\section{Rest of the world utility block}

Equations (52) and (53) show that the rest of the world has a Cobb-Douglas utility function. Notice that the rest of the world consumes the domestic (i.e., exports) and imported varieties of each good. Goods are distinguished between tradable (set st) and non-tradable (set snt). For the former, the rest of the world is indifferent between its own production (i.e, imports) and the domestic production (i.e., exports). Consequently, the export price for tradable goods is fixed at the world price (equations (54) and (55)). For the non-tradable goods, it is assumed that the rest of the world differentiates between the domestic and foreign varieties of the same good using a CES function (equations (56) and (57)). ${ }^{27}$ Equation (58) computes the price of each Armington composite good consumed by the rest of the world.

$$
\begin{gathered}
P A R O W_{s} Q A R O W_{s}=\alpha_{s}^{R O W} \text { PUTROW } \cdot Q U T R O W \\
\text { QUTROW }=\beta^{R O W} \prod_{s} Q A R O W_{s}^{\alpha_{s}^{R O W}}
\end{gathered}
$$

for tradable goods (st),

$$
\begin{gathered}
Q A R O W_{s t}=Q D R O W_{s t}+Q M R O W_{s t} \\
P M_{s t}=P U E X P_{s t}
\end{gathered}
$$

for non-tradable goods (snt),

$$
Q A R O W_{s n t}=\phi_{s n t}^{R O W}\left(\delta_{s n t}^{M R O W} Q M R O W_{s n t}^{-\rho_{s n t}^{R O W}}+\delta_{s n t}^{D R O W} Q D R O W_{s n t}^{-\rho_{s n t}^{R O W}}\right)^{-\frac{1}{\rho_{s n t}^{R O W}}}
$$

$$
\frac{Q M R O W_{s n t}}{Q D R O W_{s n t}}=\left(\frac{P U E X P_{s n t}}{P M_{s n t}} \frac{\delta_{s n t}^{M R O W}}{\delta_{s n t}^{D R O W}}\right)^{\frac{1}{1+\rho_{s n t}^{R O W}}}
$$

for all goods s,

$$
P A R O W_{s} Q A R O W_{s}=P M_{s} Q M R O W_{s}+P U E X P_{s} Q D R O W_{s}
$$

\section{Households bond savings block}

The households "produce" their portfolio of financial savings by combining bonds issued by the government and the rest of the world using a Cobb-Douglas technology (equations (59) and (60)).

27 Alternatively, a Leontief function can be used. 


$$
\begin{gathered}
\text { PBOND }_{b} Q B O N D H H D_{b h}=\alpha_{b h}^{H B O N D} \text { PBONDTOTHHD }{ }_{h} \text { OBONDTOTHHD }_{h} \\
\text { QBONDTOTHHD } \\
h=\beta_{h}^{H B O N D} \prod_{b} Q B O N D H H D_{b h}^{\alpha_{b h}^{H B O N D}}
\end{gathered}
$$

\section{Government bond savings block}

Similarly to the households, the government financial savings is a Cobb-Douglas function of the bonds issued by the households and the rest of the world (equations (61) and (62)).

$$
\begin{gathered}
P_{B O N D_{b} Q B O N D G O V_{b}}=\alpha_{b}^{G B O N D} P B O N D T O T G O V . Q B O N D T O T G O V \\
\text { QBONDTOTGOV }=\beta^{G B O N D} \prod_{b} Q B O N D G O V_{b}^{\alpha_{b}^{G B O N D}}
\end{gathered}
$$

\section{Rest of the world bond savings block}

The rest of the world also "produces" its financial savings by combining bonds issued by the households and the government using a Cobb-Douglas function (equations (63) and (64)). The variable FIXBONDROW is kept fixed or not depending on the model closure rule (see below).

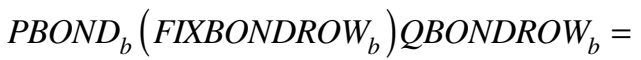

$$
\begin{aligned}
& \alpha_{b}^{\text {FBOND }} \text { PBONDTOTROW.QBONDTOTROW } \\
& Q B O N D T O T R O W=\beta^{F B O N D} \prod_{b} Q B O N D R O W_{b}^{\alpha_{b}^{F B O N D}}
\end{aligned}
$$

\section{Households budget constraint block}

Households spend fixed shares of their income in (utility) consumption (equation (65)), investment (equation (66)), and bonds (equation (67)). Equation (68) shows that the (full; i.e., including leisure) income of household $\mathrm{h}$ is the sum of factorial income, the value of leisure, the value of the issued bonds, the transfers received from the government, and the transfers received or made as a consequence of the regulatory regime if the household is the owner of the physical capital in the regulated sectors. Notice that the factorial income is computed as the supply excluding unemployment $\left(U_{f}\right)$ times the factor net price. Notice that households consume the "utility" good produced in equation (32).

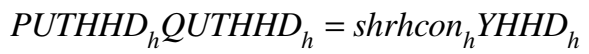




$$
\begin{gathered}
\text { PUTINV.QINVHHD } \text { Shrhinv }_{h} \text { YHHD }_{h} \\
\text { PBONDTOTHHD } \text { QBONDTOTHHD }_{h}=\text { shrhbond }_{h} \text { YHHD }_{h} \\
\text { YHHD } \\
\text { SH }_{f} \text { WF }_{f} \text { QFACSUP }_{h f}\left(1-U_{f}\right) \\
+\sum_{\text {flab }} \text { WF }_{\text {flab }} \text { QLEISURE } \\
+\sum_{b} \text { PBOND }_{b} \text { QBONDENDOW }_{h b} \\
+ \text { PGTRAN.QGTRANENDOW }_{h} \\
+ \text { shrtranreg }_{h}(\text { TRANREGA }+ \text { TRANREGF })
\end{gathered}
$$

\section{Government budget constraint block}

The government spends a fixed proportions of its income in consumption (equation (69)), investment (equation (70)), bonds (equation (71)), and transfers to the households (equation (72)). The government income is the sum of tax revenue, factorial income, income from the issued bonds, and transfers received or made as a consequence of the regulatory regime when the government is owner of physical capital in regulated sectors (equation (73)). In order to model the transfers from the government to the households, it is assumed that the latter have an endowment of the good QGTRAN demanded only by the former.

The variables FIXGCON, FIXGINV and FIXGBOND are used to choose between alternative closure rules for the government. When they are fixed and equal to zero, all the government demands are endogenous. When they are flexible and QUTGOV, QINVGOV and $Q B O N D T O T G O V$ are fixed, any increase in the government income will be transferred to the households. However, the government will have to finance any change in the price of QUTGOV, QINVGOV and QBONDTOTGOV. This last closure rule was used in the computation of the MCPF. Notice that the variables FIXGCON, FIXGINV and FIXGBOND can be seen as tax rates that generate tax revenue collected by the government (equation (73)). ${ }^{28}$

$$
\begin{aligned}
& \text { PUTGOV }(1+\text { FIXGCON }) \text { QUTGOV }=\text { shrgcon.YGOV } \\
& \text { PUTINVG }(1+\text { FIXGINV }) \text { QINVGOV = shrginv.YGOV }
\end{aligned}
$$

PBONDTOTGOV $(1+$ FIXGBOND) QBONDTOTGOV = shrgbond.YGOV

28 This formulation is equivalent to fixing the variables $Q U T G O V, Q I N V G O V$, and $Q B O N D T O T G O V$ at the same time that equations (69), (70) and (71) are dropped from the model. 


$$
\begin{aligned}
& \quad \text { PGTRAN.QGTRAN = shrgtran.YGOV } \\
& \text { YGOV }=\text { TREV } \\
& +\sum_{f} W_{f} Q F A C S U P_{g o v, f}\left(1-U_{f}\right)+ \\
& +\sum_{b} \text { PBOND }_{b} Q B O N D E N D O W_{\text {gov }, b} \\
& + \text { shrtranreg }_{\text {gov }}(\text { TRANREGA }+ \text { TRANREGF }) \\
& + \text { FIXGCON.PUTGOV.QUTGOV } \\
& + \text { FIXGINV.PUTINVG.QINVGOV } \\
& + \text { FIXGBOND.PBONDTOTGOV.QBONDTOTGOV }
\end{aligned}
$$

\section{Rest of the world budget constraint block}

The rest of the world spends fixed shares of its income in consumption (equation (74)), investment (equation (75)), and bonds savings (equation (76)). The income of the rest of the world is computed as the sum of factorial income including factor FSTAR, the income from the issued bonds, and the transfers that receives or makes as a consequence of the regulatory regime if the rest of the world is the owner of physical capital in the regulated sectors (equation (77)).

$$
\begin{aligned}
& \text { PUTROW.QUTROW }=\text { shrfcOn.YROW } \\
& \text { PUTINV.QINVROW }=\text { shrfinv.YROW }
\end{aligned}
$$

$$
\text { PBONDTOTROW.QBONDTOTROW = shrfbond.YROW }
$$

$$
\begin{aligned}
& \text { YROW }=\sum_{f} W_{f} \text { QFACSUP }_{\text {row }, f}\left(1-U_{f}\right)+\sum_{b} \text { PBOND }_{b} Q B O N D E N D O W_{\text {row }, b} \\
& + \text { WFSTAR.QFSTARENDOW }+ \text { shrtranreg }_{\text {row }}(\text { TRANREGA + TRANREGF })
\end{aligned}
$$

\section{Tax revenue block}

This block has only one equation that computes the total tax revenue. The model identifies the following tax instruments: factor tax use, production tax for the different uses, value added tax on imports and domestic products, tariffs, and direct tax on household income. 


$$
\begin{aligned}
& T R E V=\sum_{\text {fmovil }, s} t f_{\text {fmovil,s }} W F_{\text {fmovil }} Q F_{\text {fmovil,s }} \\
& +\sum_{\text {fespec }, s} t f_{\text {fespec }, s} W F D I F_{\text {fespe,s }} Q F_{\text {fespe,s }} \\
& +\sum_{s} \text { tauint }_{s} \text { PUINT }_{s} Q D U I N T_{s} \\
& +\sum_{s} \text { taufin }_{s} \text { PUFIN }_{s} \text { QDUFIN } \\
& +\sum \text { tauinv }_{s} \text { PUINV }_{s} Q D U I V_{s} \\
& +\sum_{s} \text { tauexp }_{s} \text { PUEXP }_{s} Q D U E X P_{s} \\
& +\sum_{s^{\prime} s}\left(\text { tmint }_{s^{\prime} s}+\text { tivamint }_{s^{\prime} s}\right) P M_{s^{\prime}} \text { QMINT } T_{s^{\prime} s} \\
& +\sum_{s}\left(\text { tmhhd }_{s h}+\text { tivamhhd }_{s h}\right) P M_{s} Q M H H D_{s h} \\
& +\sum\left(\text { tmgov }_{s}+\text { tivamgov }_{s}\right) P M_{s} Q M G O V_{s} \\
& +\sum\left(\text { tminv }_{s}+\text { tivaminv }_{s}\right) P M_{s} Q M I N V_{s} \\
& +\sum_{s}^{s}\left(\text { tminvg }_{s}+\text { tivaminvg }_{s}\right) P M_{s} Q M I N V G_{s} \\
& +\sum_{h} t d_{h} \mathrm{PCONHHD}_{h} \mathrm{QCONHHD}_{h} \\
& +\sum_{s} \text { tivauint }_{s} \text { PVA }_{s} Q V A U I N T_{s} \\
& +\sum_{s} \text { tivaufin }_{s} \text { PVA }_{s} \text { QVAUFIN } \\
& +\sum \text { tivauinv }_{s} \text { PVA }_{s} Q V A U I N V_{s} \\
& +\sum_{s} \text { tivauexp } P_{s} A_{s} Q V A U E X P_{s} \\
& +\sum_{s} \text { tiibbuint }_{s} \text { PUINT }_{s} \text { QDUINT } \\
& +\sum \text { tiibbufin }_{s} \text { PUFIN }_{s} \text { QDUFIN }_{s} \\
& +\sum \text { tiibbuinv }{ }_{s} \text { PUINV }_{s} Q D U I N V_{s} \\
& +\sum_{s}^{s} \text { tiibbuexp } \text { PUEXP }_{s} \text { QDUEXP }
\end{aligned}
$$




\section{Specific factor block}

Equation (79) computes the average wage of the sector-specific factors. The average wage appears in the institutional income equations.

$$
\left.\begin{array}{c}
W F_{f}\left(\sum_{i} Q F A C S U P_{i f}-Q U N E M P_{f}\right. \\
\sum_{s} W F D I F_{f s} Q F_{f s}
\end{array}\right)=f \in \text { fespec }
$$

\section{Unemployment block}

This block comprises the equations that allow to assume the existence of unemployment with a minimum real wage (i.e., the real wage is downward rigid). Equation (80) defines the consumer price index. ${ }^{29}$ Equation (81) defines a consumer price index that only includes domestic goods; the weights are computed as the share of each good in final consumption. Equation (82) defines the real wage. Equation (83) computes the unemployment rate as the ratio between the unemployed and the labor supply. Equations (84) and (85) set a lower bound for the real wage and unemployment rate, respectively. Finally, equation (86) is a complementarity relation that allows considering two regimes in the market of the factor with unemployment: i) the real wage is equal to the minimum and there is unemployment, or ii) the real wage is above the minimum and there is no unemployment. When the initial unemployment is zero (i.e., full employment is assumed), equation (86) holds always by making zero the unemployment.

$$
\begin{gathered}
\text { CPIARMING }=\sum_{s h} \text { cwtsarming }_{s h} \text { PAHHD }_{s h} \\
\text { CPI }=\sum_{s} c w t s_{s} \text { PUFIN }_{s} \\
\text { WFREAL }_{f}=\frac{W F_{f}}{\text { CPIARMING }} \\
U_{f}=\frac{\text { QUNEMP }_{f}}{\sum_{i} \text { QFACSUP }_{i f}} \\
\text { WFREAL }_{f} \geq \text { WFREAL }_{f}^{0} \\
\text { QUNEMP }_{f} \geq 0
\end{gathered}
$$

29 Notice that, as a consequence of assuming that the domestic/imported composition varies between households, each household faces a different price PAHHD(s,h). 


$$
\left(\text { WFREAL }_{f}-\text { WFREAL }_{f}^{0}\right) Q U N E M P_{f}=0
$$

\section{Equilibrium conditions block}

This block contains all the equilibrium conditions in the model. They equate the supply and demand in the different markets. Equations (87) and (88) refer to the market of the factor used in the production of domestic and imported goods, respectively. Equation (89) shows the equality between the supply of value added and the sum of the value added demands for the different uses of the domestic production. Equation (90) is similar to the previous one but refers to intermediate inputs. Equation (91) is the equilibrium condition in the market for imports. Notice that the demand for imports of the rest of the world is included. Equations (92) to (95) are the equilibrium conditions in the markets for domestic production. For example, equation (95) shows that the domestic production for exports $\left(Q D U E X P_{s}\right)$ is equal to the demand for domestic production by the rest of the world $\left(Q D R O W_{s}\right)$. Equations (96) and (97) equate the supply and demand of private and public investment, respectively. Equation (98) is the equilibrium condition in the market for bond b. Finally, equation (99) equates the supply and demand of transfers from the government to the rest of institutions included in the model.

$$
\begin{aligned}
& \sum_{s} Q F_{f s}+Q U N E M P_{f}=\sum_{i} Q F A C S U P_{i f} \\
& \text { QFSTARENDOW }=\sum_{s} Q_{F S T A R} \\
& Q V A_{s}=Q V A U I N T_{s}+Q_{V A U F I N}+Q V A U I N V_{s}+Q V A U E X P_{s} \\
& \text { QINTA }_{s}=\text { QINTAUINT }_{s}+\text { QINTAUFIN }_{s}+\text { QINTAUINV }_{s}+\text { QINTAUEXP }_{s} \\
& Q M T O T_{s}=\sum_{s^{\prime}} Q M I N T_{s s^{\prime}}+\sum_{h} Q M H H D_{s h}+Q M G O V_{s}+Q M I N V_{s}+Q M R O W_{s} \\
& \sum_{s^{\prime}} Q D I N T_{s s^{\prime}}=Q D U I N T_{s} \\
& \sum_{h} Q D H H D_{s h}+Q D G O V_{s}=Q D U F I N_{s} \\
& Q D I N V_{s}+Q D I N V G_{s}=Q D U I N V_{s} \\
& Q D R O W_{s}=Q D U E X P_{s} \\
& \text { QUTINV }=\sum_{h} Q I N V H H D_{h}+\text { QINVROW }
\end{aligned}
$$




$$
\begin{gathered}
\text { QUTINVG }=\text { QINVGOV } \\
\sum_{i} \text { QBONDENDOW }_{i b}=\sum_{h} \text { QBONDHHD }_{b h}+\text { QBONDGOV }_{b}+\text { QBONDROW }_{b} \\
\text { QGTRAN }=\sum_{i} Q G T R A N E N D O W_{i}
\end{gathered}
$$

\section{Regulation block}

Equations (100) and (101) are used to compute the transfer (i.e., implicit tax revenue) necessary to regulate the price of good $s$ and the wage of factor $f$ in sector $\mathrm{s}$, respectively. These transfers are part of the income of institutions (see equations (68), (73) and (77)). Notice that the value of those transfers can be negative. Equations (102) to (105) compute the price in terms of the CPI of the different possible uses for each good. When a sector is regulated by price-cap, those prices are kept constant. Equation (106) defines the real wage of factor $f$ in the sector s. Equations (107) to (111) are used to define the regulated real prices in terms of the price of the factor owned by the rest of the world.

$$
\begin{aligned}
& \text { TRANREGF }=\sum_{\text {fmovil }, s} R E G F_{\text {fmovil,s }} W F_{\text {fmovil }} Q F_{\text {fmovil }, s} \\
& +\sum_{\text {fespec }, s} R E G F_{\text {fespec,s }} W F D I F_{\text {fespec }} Q F_{\text {fespec }, s} \\
& \text { TRANREGA }=\sum_{s} \text { REGAUINT }_{s} \text { PUINT }_{s} \text { QDUINT } \\
& +\sum_{s} \text { REGAUFIN }_{s} \text { PUFIN }_{s} \text { QDUFIN }_{s} \\
& +\sum_{s} R E G A U I N V_{s} \text { PUINV }_{s} Q D U I N V_{s} \\
& +\sum_{s} R E G A U E X P_{s} P_{U E X}{ }_{s} Q D U E X P_{s} \\
& \text { PUINTREAL }_{s} \text { CPIARMING }=\text { PUINT }_{s} \\
& \text { PUFINREAL }_{s} \text { CPIARMING } \text { PUFIN }_{s} \\
& \text { PUINVREAL } L_{s} \text { CPIARMING }=P \text { UINV }_{s} \\
& \text { PUEXPREAL } L_{s} \text { CPIARMING }=P U E X P_{s} \\
& \text { WFDIFREAL } f_{s s} \text { CPIARMING }=W_{F D I F}
\end{aligned}
$$

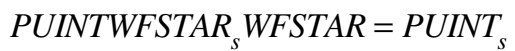




$$
\begin{aligned}
& \text { PUFINWFSTAR }_{s} \text { WFSTAR }=\text { PUFIN }_{s} \\
& P U I N V W F S T A R_{s} W F S T A R=P U I N V_{s} \\
& \text { PUEXPWFSTAR }_{s} \text { WFSTAR }=\text { PUEXP }_{s} \\
& W_{F D I F W F S T A R}{ }_{f s} W F S T A R=W F D I F_{f s}
\end{aligned}
$$

\section{Regulated sectors}

The model considers two alternative regulatory regimes: price cap, and cost-plus or rate of return regulation. In the first case, the real price (i.e., in terms of the CPI) of the regulated good is fixed at the same time that the variables REGAUINT(reg), REGAUFIN(reg), REGAUINV(reg) y REGAUEXP(reg) are flexible. In the second case, the real wage of the physical capital in the regulated sector is fixed at the same time that the variable REGF(fcap,reg) is flexible. In both cases, the variables REGAUINT(reg), REGAUFIN(reg), REGAUINV(reg) and REGAUEXP(reg), and REGF(fcap,reg) operate as (implicit) taxes that generate a tax revenue that is collected by the owners (households, government, rest of the world) of the physical capital in the regulated sectors. Notice that the tax collection can be negative (i.e., subsidy).

\section{Closure rule}

Assuming that all goods are tradable, the model has the following dimensions in terms of variables and equations.

\begin{tabular}{|l|c|c|c|c|c|c|c|c|c|c|c|}
\hline & $\mathrm{s}$ & $\mathrm{s} \times \mathrm{s}$ & $\mathrm{b}$ & $\mathrm{b} \times \mathrm{h}$ & $\mathrm{f}$ & $\mathrm{fx} \mathrm{s}$ & $\mathrm{h} \times \mathrm{f}$ & $\mathrm{h}$ & $\mathrm{i} \mathrm{b} \mathrm{b}$ & $\mathrm{s} \times \mathrm{h}$ & 1 \\
\hline Variables & 51 & 4 & 4 & 1 & 4 & 5 & 2 & 9 & 2 & 4 & 30 \\
Equations & 47 & 4 & 3 & 1 & 4 & 3 & 2 & 8 & 1 & 4 & 25 \\
\hline Difference & 4 & 0 & 1 & 0 & 0 & 2 & 0 & 1 & 1 & 0 & 5 \\
\hline
\end{tabular}

In order to have a square model with the same number of variables and equations, it is necessary to fix the value of $4 \mathrm{~s}+\mathrm{b}+2(\mathrm{f} \mathrm{x} \mathrm{s})+\mathrm{h}+(\mathrm{i} \mathrm{x} \mathrm{b})+5$ variables. We select the following:REGAUINT REGAUFIN $_{s}$, REGAUINV $_{s}$ and REGAUEXP Rhen $_{s}$ where are no sectors regulated by price-cap; $R E G F_{f s}$ when there are no sectors regulated by the rate of return on physical capital; $W F D I F_{f s}$ for the mobile factors between sectors and $Q F_{f s}$ for the sector-specific factors; $Q F S U P_{i f}$ (includes unemployment) for the institutions different from the households that do not face a labor-leisure choice and QFSTARENDOW so that factor endowments are fixed; $Q G T R A N E N D O W_{h}$ so that the share of each household in the government transfers is fixed; $Q B O N D E N D O W_{i b}$ so that the endowment of bonds $\mathrm{b}$ of each institution i is fixed; FIXBONDROW ${ }_{b}$ in order to have a flexible demand for bonds by the rest of the world; and QUTGOV, 
QINVGOV and $Q B O N D T O T G O V$ in order to fix the government demand for goods, investment, and bonds.

The model numeraire is the factor FSTAR that the rest of the world employs to produce imports; its wage is fixed at one. Then, by virtue of Walras law, an equation can be dropped from the model. Alternatively, an endogenous variable (i.e., WALRAS) can be added to the model; its value must be zero in equilibrium.

Figure A.1 sums up the structure of the model for the production side that is utilized for final consumption (i.e., household and government consumption). The other destinations for domestic production are modeled in the same way. Figure A.2 presents the decomposition of households' expenditure in consumption goods (traditional utility function), investment in physical assets (indicated as "Investment") and in financial instruments (called "Savings"). The government, as well as the rest of the world, is modeled as a household. The bottom part of each box shows the corresponding variable in the model mathematical statement. The following abbreviations are used for the functional forms: LF stands for Leontief, CD for Cobb-Douglas, and CES for Constant Elasticity of Substitution. The figure shows, for example, that labor and capital are combined with a Cobb-Douglas production function to produce value added. See the Appendix for a detailed presentation of the model.

FIGURE A.1

PRODUCTION SIDE - FINAL USE

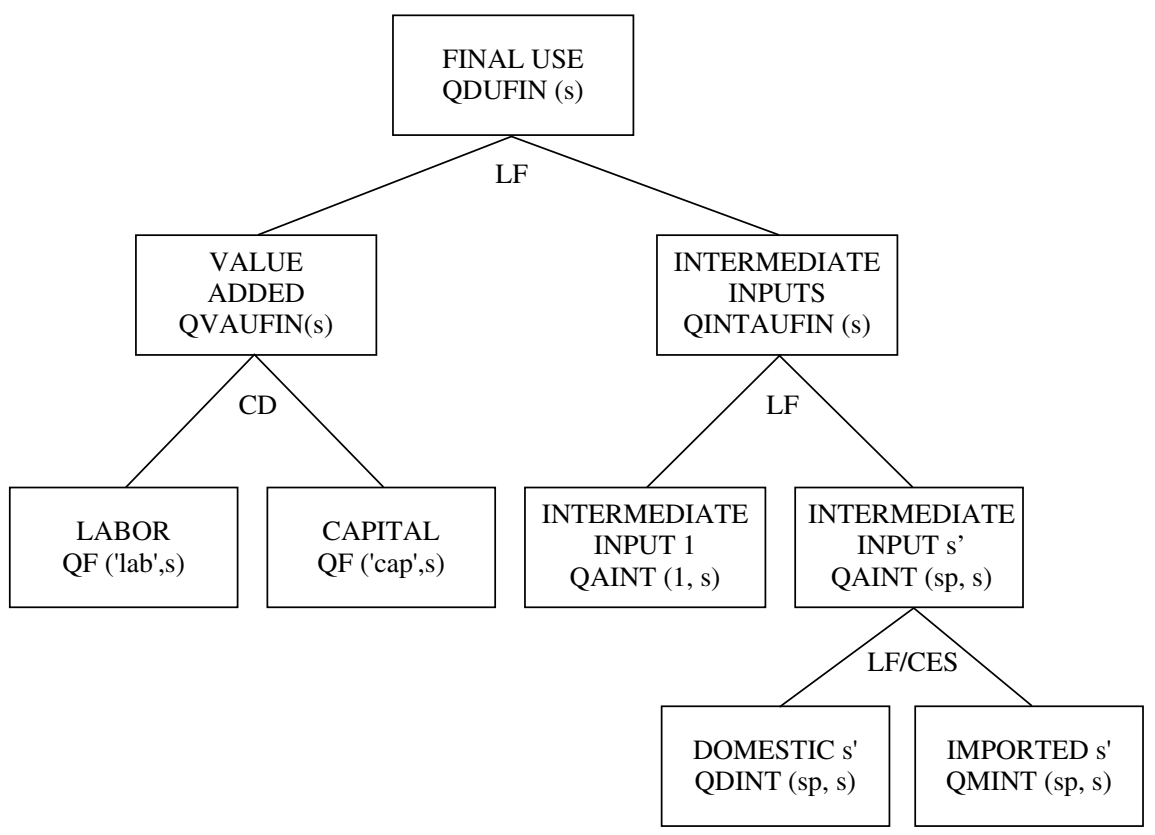


FIGURE A.2

CONSUMPTION SIDE - HOUSEHOLD

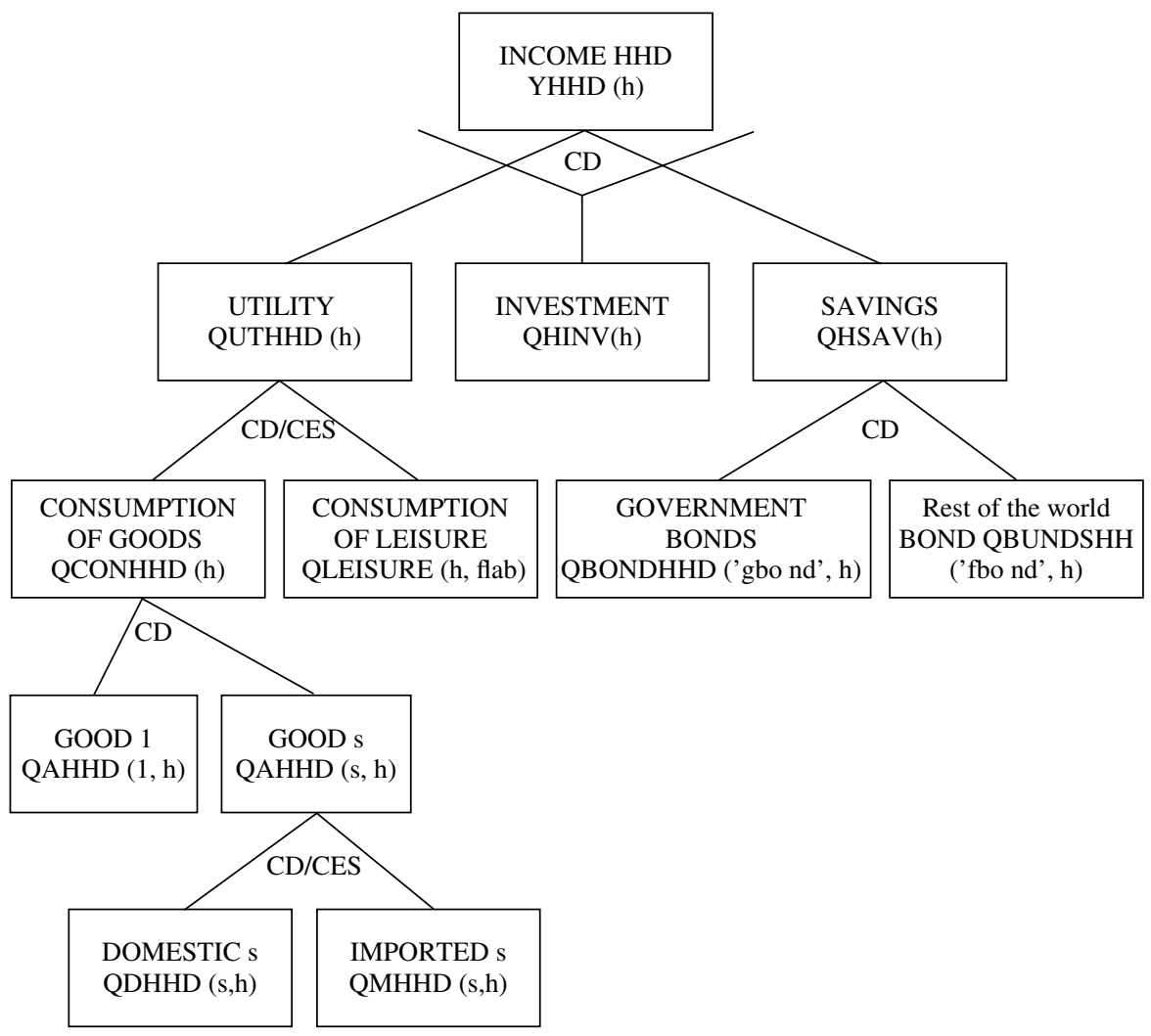

